\title{
Global changes in extreme events: regional and seasonal dimension
}

\author{
Boris Orlowsky • Sonia I. Seneviratne
}

Received: 30 November 2010 / Accepted: 18 May 2011 / Published online: 22 July 2011

(C) The Author(s) 2011. This article is published with open access at Springerlink.com

\begin{abstract}
This study systematically analyzes the complete IPCC AR4 (CMIP3) ensemble of GCM simulations with respect to changes in extreme event characteristics at the end of the 21st century compared to present-day conditions. It complements previous studies by investigating a more comprehensive database and considering seasonal changes beside the annual time scale. Confirming previous studies, the agreement between the GCMs is generally high for temperature-related extremes, indicating increases of warm day occurrences and heatwave lengths, and decreases of cold extremes. However, we identify issues with the choice of indices used to quantify heatwave lengths, which do overall not affect the sign of the changes, but strongly impact the magnitude and patterns of projected changes in heatwave characteristics. Projected changes in precipitation and dryness extremes are more ambiguous than those in temperature extremes, despite some robust features, such as increasing dryness over the Mediterranean and increasing heavy precipitation over the Northern high latitudes. We also find that the assessment of projected changes in dryness depends on the index choice, and that models show less agreement regarding changes in soil moisture than in the commonly used 'consecutive dry days' index, which is based on precipitation data only. Finally an analysis of the scaling of changes of extreme temperature quantiles with global, regional and seasonal warming shows that much of the extreme quantile changes are due to a seasonal scaling of the regional annual-mean warming. This emphasizes the importance of the seasonal time scale also for extremes. Changes in extreme quantiles of temperature on land scale
\end{abstract}

Electronic supplementary material The online version of this article (doi:10.1007/s10584-011-0122-9) contains supplementary material, which is available to authorized users.

B. Orlowsky $(\bowtie) \cdot$ S. I. Seneviratne

Institute for Atmospheric and Climate Science, ETH Zurich,

Universitaetsstr. 16, 8092 Zurich, Switzerland

e-mail: boris.orlowsky@env.ethz.ch

S. I. Seneviratne

e-mail: sonia.seneviratne@env.ethz.ch 
with changes in global annual mean temperature by a factor of more than 2 in some regions and seasons, implying large changes in extremes in several countries, even for the commonly discussed global $2^{\circ} \mathrm{C}$-warming target.

\section{Introduction}

Implications of global warming for changes in extreme weather and climate events are of major concern for society, in particular in relation to impacts on economy, ecosystems and health (e.g., Patz et al. 2005; Halsnaes et al. 2007; Lenton et al. 2008; Loarie et al. 2009; Sherwood and Huber 2010). However, since extreme events are typically rare events, only limited observational data are available for their study. Climate models exhibit a correspondingly large uncertainty in their simulation, especially for non-temperature related extremes (Tebaldi et al. 2006; Beniston et al. 2007).

The investigation by Tebaldi et al. (2006, T06 hereafter) is one of the most prominently cited studies on changes in climate extremes based on the Intergovernmental Panel on Climate Change (IPCC) 4th Assessment Report (AR4) Global Climate Model (GCM) scenarios. In T06, a standard set of extreme indices defined in Frich et al. (2002) was investigated for a subset of nine GCMs that contributed scenarios to the IPCC AR4. The study compared present-day and future climate model simulations based on several emission scenarios from the IPCC Special Report on Emission Scenarios (SRES, Nakicenovic and Swart 2001). The analysis revealed a significant agreement between the models regarding changes of temperature-related extremes, such as increases in the occurrence of hot days, changes in the length of heatwaves, and decreases in number of frost days. For precipitation extremes the agreement between the models was weaker, and the associated uncertainty was of a similar order of magnitude as the uncertainty range induced by the choice of the different emission scenarios.

While the ensemble analysis in T06 provided a systematic overview of global patterns of extreme event tendencies, some important aspects for links to impacts and the assessment of the overall AR4 ensemble uncertainty were not considered:

- The study only considered annual changes in extremes, but seasonal changes in extremes are often more relevant for impacts (e.g., Alexander et al. 2006; Menzel et al. 2006).

- Only nine of the overall ensemble of 23 GCMs contributing simulations to the IPCC AR4 could be considered at the time.

- The global relevance of certain employed indices has been lately debated, e.g. in the case of the maximum heatwave duration index (HWDI) for heatwaves, and the maximum consecutive dry days (CDD) for droughts.

The overall aim of our study is to provide an updated overview of changes in extreme event indices in the IPCC AR4 GCM ensemble. We extend the T06 analysis and complete it with respect to the following aspects:

- Extension of the analysis to seasonal time scales.

- Inclusion of other variables and indices, including specific quantiles for temperature and precipitation distributions, and evaluation of pertinence of some of 
the Frich et al. (2002) indices for assessing changes in extremes on the global scale.

- Consideration of the complete set of available GCMs for the A2 scenario.

In addition, we propose and illustrate here a possible approach for evaluating the scaling between seasonal-scale and regional-scale changes in extremes and changes in global mean annual temperature. This question is of importance, since regions present a large range of sensitivity to global climate change. It is also of particular relevance in the context of setting global mean-temperature targets for mitigation (e.g., " $2{ }^{\circ} \mathrm{C}$ target").

We restrict our analysis to the SRES-A2 emission scenario, which is expected to produce the strongest climate change signal among all typically used SRES scenarios at the end of the 21st century. However, anthropogenic greenhouse gas emissions since 2000 have been near the upper limit of the emission range spanned by the SRES scenarios, attenuating the perception of the A2 scenario as an unrealistic 'worst case' (Le Quere et al. 2009; Manning et al. 2010). Furthermore, earlier studies found that the emission scenario mainly affects the strength of change in extreme event indices, while the spatial patterns of these changes are rather robust (see T06 and references therein).

This article is organized as follows: Section 2 describes the GCM data and the analyses performed in our study. Section 3 displays and discusses patterns of change of several extreme indices and related variables for annual and seasonal changes. Section 4 exemplarily analyzes seasonal changes of extreme maximum air temperature quantiles and their scaling with different contributions such as global or regional warming. Conclusions are provided in Section 5.

\section{Data and methods}

\subsection{Global circulation models (GCMs)}

The analyses are based on the complete IPCC AR4 ensemble of GCM simulations available via ftp from the server of the Coupled Model Intercomparison Project (CMIP3, see http://www-pcmdi.llnl.gov/ipcc/about_ipcc.php). On the ftp-server, data from several experiments is stored. Here we use simulations for the 20th century $(20 \mathrm{C} 3 \mathrm{M})$ and for the $21 \mathrm{st}$ century (driven by the A2 emission scenario). The 21st century runs are initialized from the year 2000 of the 20C3M runs. Combined, the two runs entail therefore a continuous climate trajectory for the two centuries. By default, three periods from these two experiments are available: 1960-2000, 20452065 and 2080-2100 (exact start and end years varying between the models).

Daily (maximum and minimum near surface air temperature $T_{\max }$ and $T_{\min }$, precipitation 'pr') and monthly (soil moisture integrated over all soil layers 'mrso', latent surface heat flux 'hfls') data was downloaded from the CMIP3 server for the available GCM runs (summarized in Table 1). The right-most column of Table 1 indicates for which variables each GCM is included. These sets differ, since the availability of variables from the simulations varies. The employed selection criteria is that, for a given variable and GCM run, data for both the $20 \mathrm{C} 3 \mathrm{M}$ and the A2 simulations are available for the same run. 


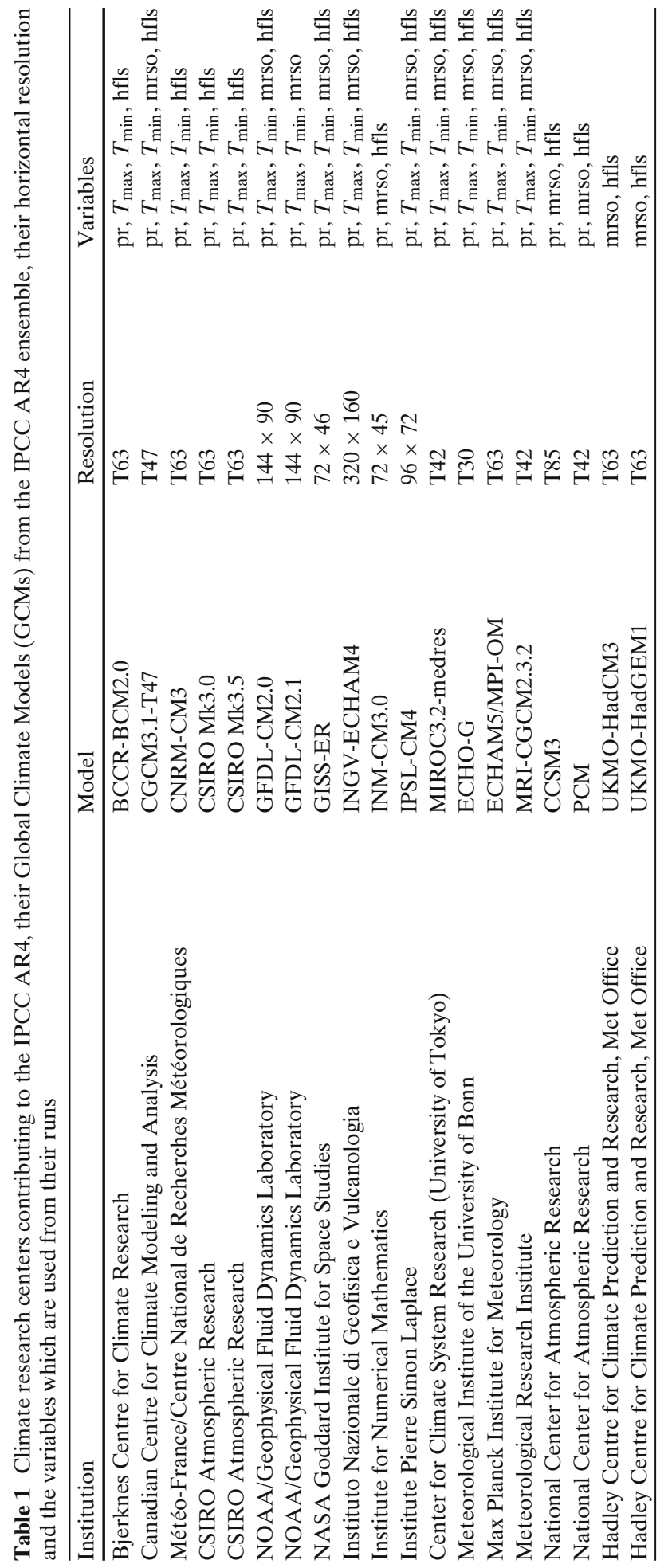




\subsection{Indices and their derivation}

This study is concerned both with annually and seasonally derived indices, for which we use the standard meteorological seasons (December to February, DJF; March to May, MAM; June to August, JJA; September to November, SON). Some of the analyzed indices are calculated per single year or season. These are essentially indices also analyzed in T06 and indices derived therefrom. Since this leads to time series with yearly time steps (each time step consisting either of the index for the entire year or of the index for one season of this year), it allows for a normalization of the indices with the interannual standard deviation of the respective models (prior to the multi-model averaging), as was done in T06 (see below). The interannual standard deviation is derived from detrended annual values of these indices for the three 20-year periods 1980-1999, 2046-2065 and 2081-2100 (see step 3 below). The interannual standard deviation is derived from detrended annual values of these indices for the three 20-year periods 1980-1999, 2046-2065 and 2081-2100 (see step 3 below). Other indices are calculated over entire periods, mainly those for which an annual estimate does not make sense such as a quantile of seasonal precipitation sums. Threshold exceedance events (with respect to fixed or quantilebased thresholds) are calculated per year or per period, depending on common practice. The climatology, that is, the annual cycle, and the climatological quantiles of each day of the year which are necessary for the derivation of some of the indices are always based on the 1961-1990 period and calculated as in T06. Results are presented for differences between the later (2081-2100) and earlier (1980-1999) time periods. The next paragraphs describe the overall computational procedures employed in this study and introduce the analyzed indices.

Derivation and mapping of the indices Adapted from the approach applied in T06, we adopt the following steps:

1. For each run of each model, the indices are calculated, either for each year of each of the three periods, or over each period separately (depending on the index, see below).

2. The difference patterns between the last period (2081-2100) and the present-day period (1980-1999) are calculated for each of the model patterns. If the indices are calculated per year, the difference between the averages over the two periods is calculated.

3. Only for the per year (T06-like) indices: The difference patterns of each model are normalized to account for the different variabilities of the models. Hence, the unit of these plots is the standard deviation. The standard deviation is derived from the yearly index values of all three periods, (1980-1999, 2046-2065, 20812100) which are centralized per period for a first order detrending. If the standard deviation is near-zero due to missing values, the thereby inflated normalized difference is later-on identified by an outlier test and not considered for the ensemble average. For the indices which are calculated for the entire periods, the difference patterns are left in their natural units.

4. The (standardized) difference patterns are interpolated to a common T42 grid.

5. If a model has several runs, the difference patterns are averaged over all runs. This gives equal weights to the models.

6. The interpolated difference patterns are averaged over all models. 
7. Significance of the changes in the model ensemble is evaluated in relation to standard IPCC likelihood levels (IPCC 2007): If at a given grid cell less than $66 \%$ of the models agree on the sign of a change, then this grid cell is left blank (gray shading); hence, the analyses are only displayed for grid cells with (at least) 'likely' changes. If at least $90 \%$ of the models agree on the sign of the change, then the grid cell is stippled ('very likely' changes). It should be noted that depending on the variables, the model agreement may not be equivalent to the likelihood level of the projections, for example when models are consistently biased (Knutti et al. 2010; Mueller et al. 2011) or the observational basis is too limited to assess the model performance (e.g. for soil moisture changes, see Seneviratne et al. 2010). Nonetheless, model agreement is one aspect considered in the evaluation of the likelihood of projections (Mastrandrea et al. 2010).

The following paragraphs describe the indices analyzed in this study. See Frich et al. (2002), Alexander et al. (2006) and T06 for further details and the interpretation of the indices.

Temperature indices The following temperature indices are calculated for each year or season separately:

- HWDImax (maximum heatwave duration index): Maximum period length per year or season of at least five consecutive days, at which $T_{\max }>$ climatology $+5 \mathrm{~K}$.

- HWDImean (mean heatwave duration index): Average period length per year or season of at least five consecutive days, at which $T_{\max }>$ climatology $+5 \mathrm{~K}$.

- WSDI (warm spell duration index): fraction of days per year or season which belong to periods of at least 6 days at which consecutively $T_{\max }>q 90$, where $q 90$ gives the climatological $90 \%$-quantile of $T_{\max }$ for that day.

- $\%$ WD (warm days): fraction of days per year or season, at which $T_{\max }>q 90$, where $q 90$ gives the climatological $90 \%$-quantile of $T_{\max }$ for that day.

- $\%$ CD (cold days): fraction of days per year or season, at which $T_{\max }<q 10$, where $q 10$ gives the climatological $10 \%$-quantile of $T_{\max }$ for that day.

- $\quad \% W N$ (warm nights): fraction of days per year or season, at which $T_{\min }>q 90$, where $q 90$ gives the climatological $90 \%$-quantile of $T_{\min }$ for that day.

- $\quad \% \mathbf{C N}$ (cold nights): fraction of days per year or season, at which $T_{\min }<q 10$, where $q 10$ gives the climatological $10 \%$-quantile of $T_{\min }$ for that day.

The following temperature statistics are calculated for each entire period (that is, seasonal indices are calculated based on the data from the corresponding seasons of the entire period pooled together and annual indices are based on data from the entire period):

- Quantiles: 10\%-, 50\%- and 90\%-quantiles of the daily $T_{\max }$ and $T_{\min }$ for each day of the year for each entire period, smoothed by a five-day running median. We analyze annual and seasonal means of these daily quantiles.

- $\boldsymbol{T}_{\max }>30^{\circ} \mathbf{C}$ (hot days): Fraction of days with $T_{\max }>30^{\circ} \mathrm{C}$ are calculated for each entire period.

- $\quad \boldsymbol{T}_{\min }>\mathbf{2 0}{ }^{\circ} \mathbf{C}$ (tropical nights): Fraction of days with $T_{\min }>20^{\circ} \mathrm{C}$ are calculated for each entire period. 
Precipitation indices The following precipitation indices are calculated for each year or season separately:

- CDD (consecutive dry days): maximum period length per year or season of days without precipitation, that is $\mathrm{pr}<1 \mathrm{~mm}$.

- Wet Day Intensity: Average precipitation amount on wet days ( $\mathrm{pr}>1 \mathrm{~mm}$ ) for each year or season.

- $\quad \mathbf{p r}>\mathbf{1 0} \mathbf{~ m m}$ (heavy precipitation): Fraction of days with $\mathrm{pr}>10 \mathrm{~mm}$ per year or season.

The following precipitation statistics are calculated for each entire period (as described for the temperature indices of entire periods):

- Quantiles: 10\%-, 50\%- and 90\%-quantiles of the annual or seasonal precipitation averages for each entire period.

- Averages: Simple annual and seasonal averages over the entire periods.

- $\quad$ pr $>$ q95: Fraction of days with pr $>q 95$ are calculated for each entire period, where $q 95$ gives the climatological $95 \%$-quantile of wet day precipitation from the reference period.

Soil moisture and evapotranspiration statistics For soil moisture (mrso), seasonal and annual averages are calculated on a per year basis. For evapotranspiration (ET), we calculate annual and seasonal averages from fields for latent heat flux (hfls) via $\mathrm{ET}=\mathrm{hfls} / \lambda$, with $\lambda=2.5 \times 10^{6} \mathrm{~J} / \mathrm{kg}$.

\section{Global patterns of changing extremes}

In contrast to previous studies such as T06, our analysis is based on the full GCM ensemble of the IPCC AR4 and extended from the annual to the seasonal scale. Results are displayed for entire years and the four seasons (DJF, MAM, JJA, SON, see Section 2.2). Like T06, we show patterns of the differences between the 20812100 and 1980-1999 time periods. Depending on the index, the data is plotted directly in the units of the variable or normalized by the standard deviations of the individual models (see Section 2.2). Note that earlier studies (T06 and references therein) suggest that these patterns are representative for a wide range of emission scenarios, which are mainly relevant for the strength of the change. Nonetheless, some threshold effects can add to changes in certain extremes (e.g. soil moisture limitation on evapotranspiration for hot extremes, see Seneviratne et al. 2010). In these cases the scaling between the scenarios may not be accurate.

The main purpose of this study is to provide a comprehensive presentation of the patterns of change in extreme event indices, rather than a thorough physical interpretation of these changes. Their discussion is therefore in many cases deferred to future work. The following subsections describe the outcome of our analysis.

\subsection{Temperature}

The annual changes of the 10 and $90 \%$ quantiles of daily $T_{\max }$ exhibit their main differences in the Northern high latitudes, where the $10 \%$ quantile has a more pronounced warming compared to the $90 \%$ quantile (Fig. 1). The seasonal perspec- 

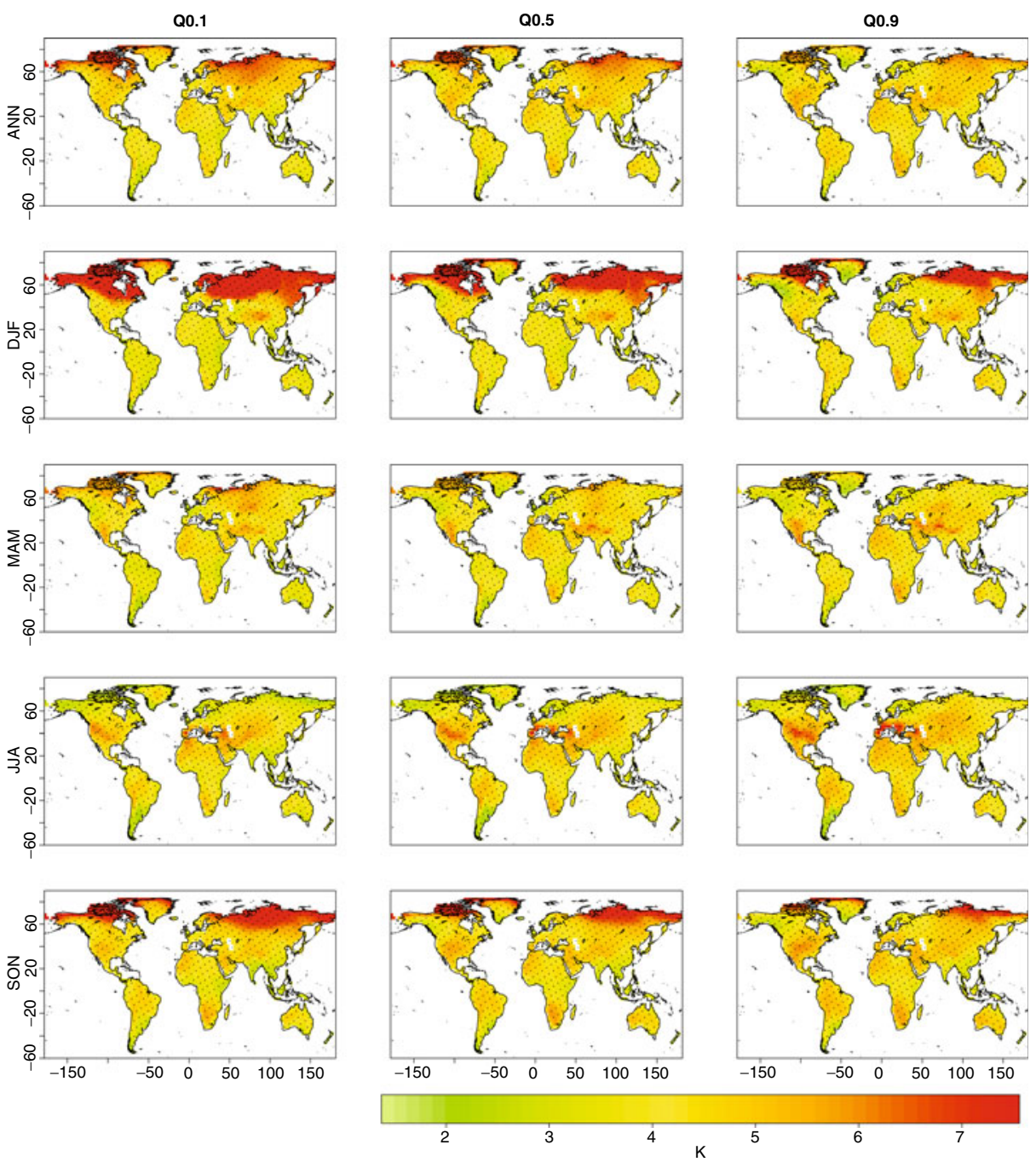

Fig. 1 Changes of three quantiles of daily $T_{\max }$ for the entire year $(A N N)$ and the four seasons $(D J F$, $M A M, J J A, S O N)$

tive reveals that the high warming of the low quantile in the high latitudes takes mainly place in boreal fall and winter. The strongest warming of the high quantile is found mainly in the mid latitudes in boreal summer and fall. The median is always in between these tendencies. These seasonal warming patterns agree well with results from other studies, which attribute them to snow and soil moisture effects (Seneviratne et al. 2006; Diffenbaugh et al. 2007; van Oldenborgh et al. 2009). A stronger warming of the hot tails of temperature distributions with decreasing soil moisture content is also a feature found in observations from Southeastern Europe (Hirschi et al. 2011). Note that the empirical estimation of the daily quantiles can lead 
to biased estimates of the quantile changes, though for moderately extreme quantiles like the $10 \%$ or $90 \%$ used here, this bias is acceptable (Zhang et al. 2005).

The changes of the corresponding $T_{\min }$ quantiles show similar patterns as the changes in $T_{\max }$ quantiles, including a similar order of magnitude (Fig. 2). However, it is striking that the warming of the higher $T_{\min }$ quantiles in mid-latitude regions is not as pronounced as for $T_{\max }$, which again points at an effect of soil moisture limitation. Indeed, soil moisture feedback on temperature acts through a limitation of daytime evapotranspiration (and consequent increase of sensible heat flux), and thus affects daytime temperature more than nighttime temperature, leading to an increase of the
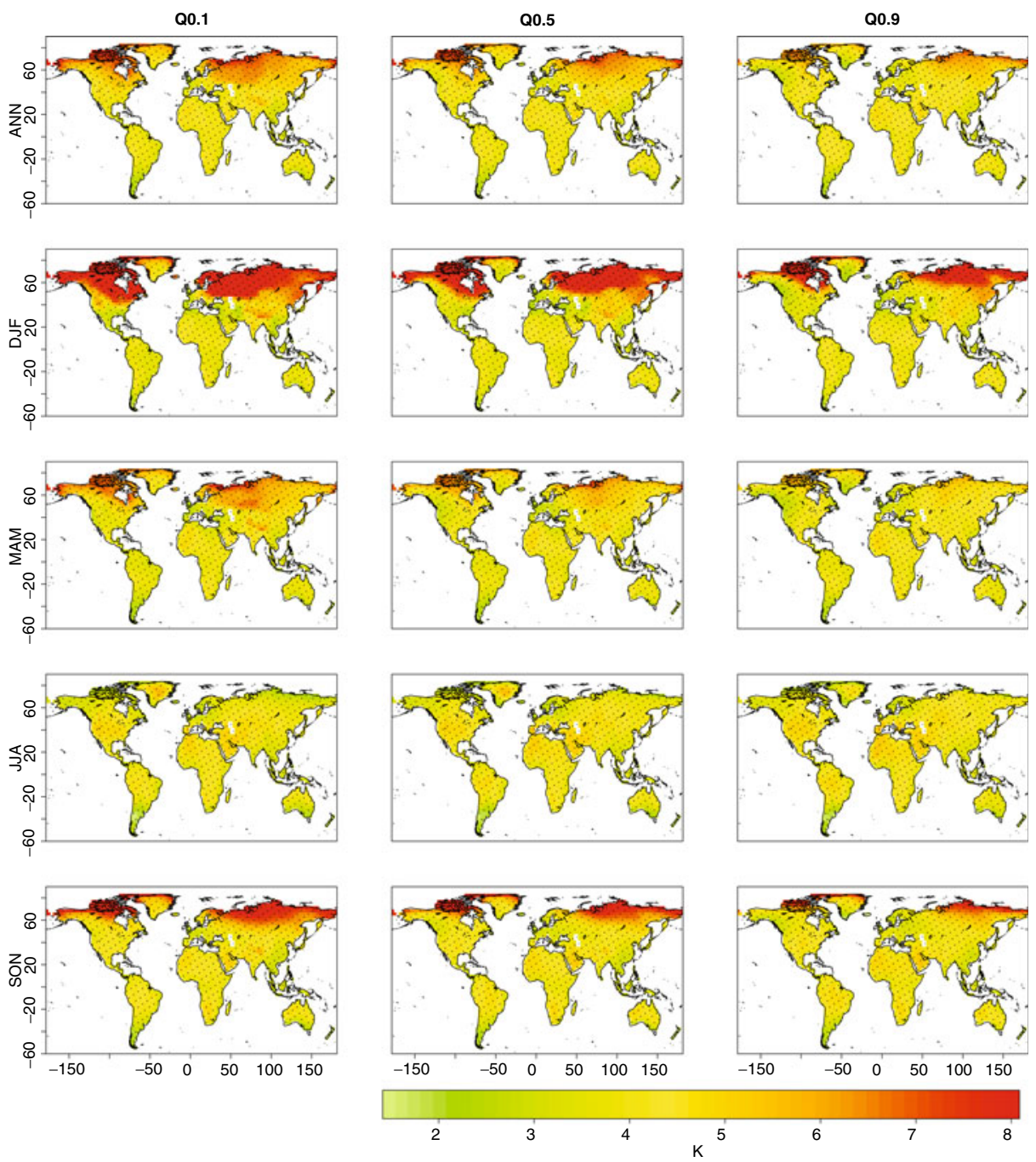

Fig. 2 Changes of three quantiles of daily $T_{\min }$ for the entire year $(A N N)$ and the four seasons $(D J F$, $M A M, J J A, S O N)$ 
diurnal temperature range if soil moisture limitation is enhanced (Zhang et al. 2009; Jaeger and Seneviratne 2010).

In Fig. 3, three extreme indices for $T_{\max }$ (fractions of warm days \%WD, cold days $\% \mathrm{CD}$ and hot days with $T_{\max }>30^{\circ} \mathrm{C}$ ) are shown. For the fraction of warm days (\%WD), all seasons approximately agree on where the strongest increases take place, although some shifts and variations are seen. The regional differences are most pronounced for JJA and SON, for which hot spots of increasing \%WD over the Western US, Northern South America, Southern and Northern Africa, the
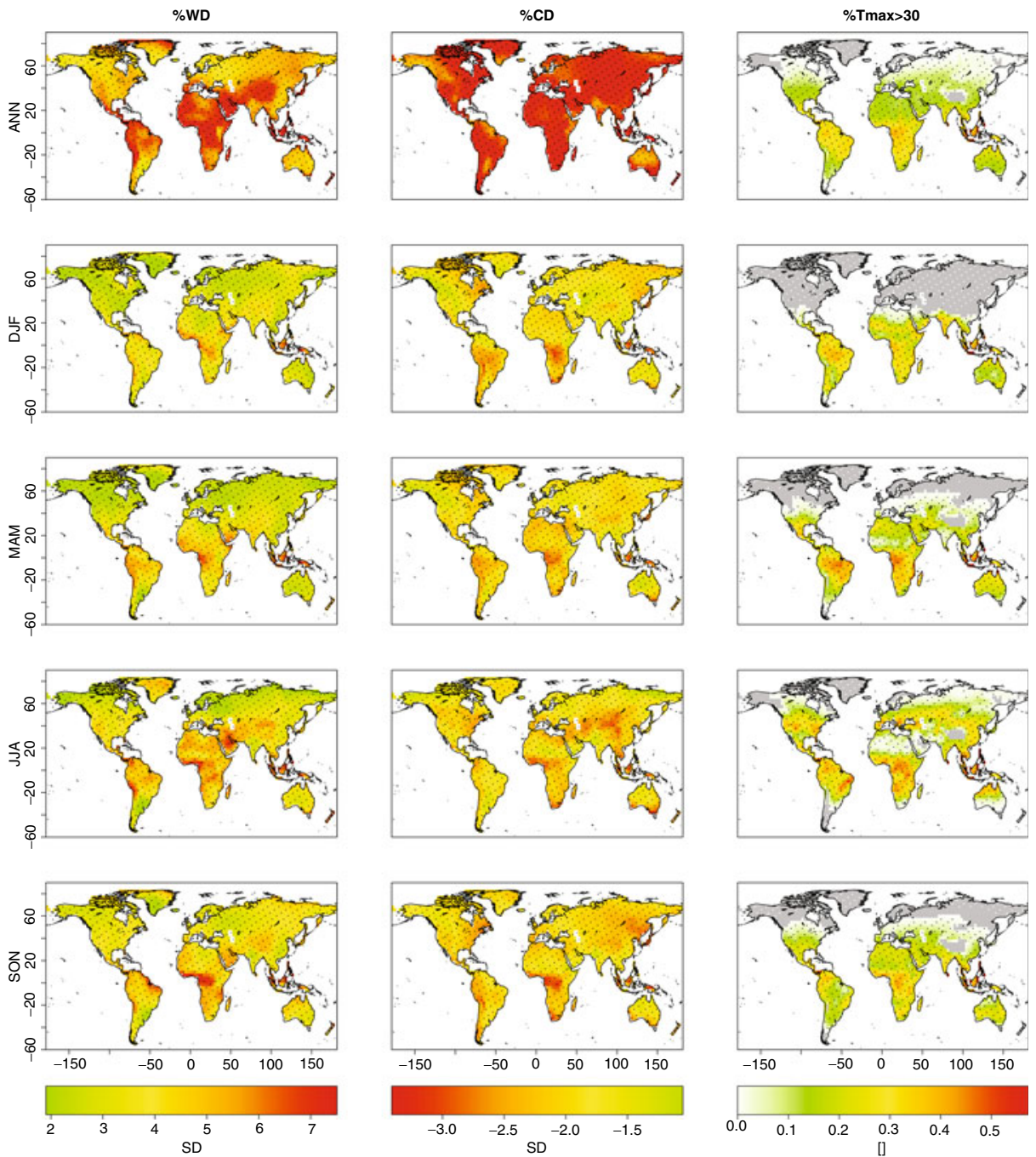

Fig. 3 Annual and seasonal changes of three indices for $T_{\max }$ : Fraction of warm days, fraction of cold days and days with $T_{\max }>30^{\circ} \mathrm{C}$. See Section 2.2 for details. White stippling indicates the areas where no $\mathrm{GCM}$ reaches the $30^{\circ} \mathrm{C}$ threshold in any of the two periods (1980-1999 and 2081-2100) 
Middle East, Central Asia, and Mediterranean Europe appear. Regions with major changes in \%WD in all seasons are found in the tropics, in particular on the Malay Archipelago and in tropical Africa. India display the largest increases in \%WD in the MAM season.

The fraction of cold days (\%CD) shows for the annual time scale very homogeneous changes on the whole globe. Large changes in \% CD on the seasonal time scales are in particular found in tropical Africa and the Malay Archipelago. The seasonal signals of both \%WD and \% CD are weaker than the annual ones. This is a result of the per model normalization by the standard deviation, which is higher for the seasons than for the entire year due to the smaller sample sizes.

The fraction of days with $T_{\max }>30^{\circ} \mathrm{C}$ increases most in equatorial Africa as well, with some additional hot spots over the Amazon and the Malay Archipelago. Depending on the season, the threshold is not reached over extended areas in the high latitudes. In Southern Europe and part of the United States, only boreal summer sees a marked increase of these days. Except for this latitudinal effect on the index, the seasonal and annual patterns are rather similar.

In Fig. 4, three extreme indices for $T_{\min }$ are shown, analogue to the indices for $T_{\max }$ in Fig. 3 (fractions of warm nights \% WN, cold nights \% CN and tropical nights with $T_{\min }>20^{\circ} \mathrm{C}$ ). Again, for the normalized two indices (warm nights and cold nights), the seasonal signals are weaker than the annual ones. For the warm nights, the greatest increase occurs over the tropics. This is probably due to the rather low temperature variability of this region (compared to higher latitudes), which means that the $90 \%$-quantile of the reference period is relatively close to the climatological mean (not shown) and is therefore easily exceeded when the mean temperature increases in the course of global warming. The pattern of the warm night index changes in T06 is confirmed by our analysis on the annual time scale and is also similar to the pattern of change in frost days $\left(T_{\min }<0^{\circ} \mathrm{C}\right)$ in T06. The seasonal patterns do not reveal any further particularities, hinting at a uniform increase throughout the year.

Less spatial differentiation is found for the patterns of change in cold nights, which globally decrease. One feature possibly worth mentioning is a relatively strong decrease over the central US in JJA. For the tropical nights $\left(T_{\min }>20^{\circ} \mathrm{C}\right)$, the by far most prominent feature is the increase over the tropics, which-mainly over Africareaches the order of magnitude of 30 percentage-points. Northern mid and high latitudes display seasonal changes mainly in JJA, since temperatures do not reach the $20^{\circ} \mathrm{C}$ threshold in other seasons. Over Africa, the areal extent of the regions with strong increases is somewhat smaller in JJA compared to other seasons, however, part of this difference is due to a reduced GCM agreement in this season which leads to more grid cells being masked out.

Figure 5 shows different heatwave indices (for maximum and average heatwave duration, HWDImax and HWDImean, and warm spell duration, WSDI) for the entire years and the seasons. Overall, most models agree on heatwave increases in almost all regions for all seasons, independently on the chosen index. Like in Fig. 3, the normalized indices show weaker seasonal signals compared to the annual signal. In this case this is not only a consequence of the normalization but also of a design problem of the indices: They are calculated for the seasons and years individually, which means that the seasonal estimates have a higher chance of heatwaves being 

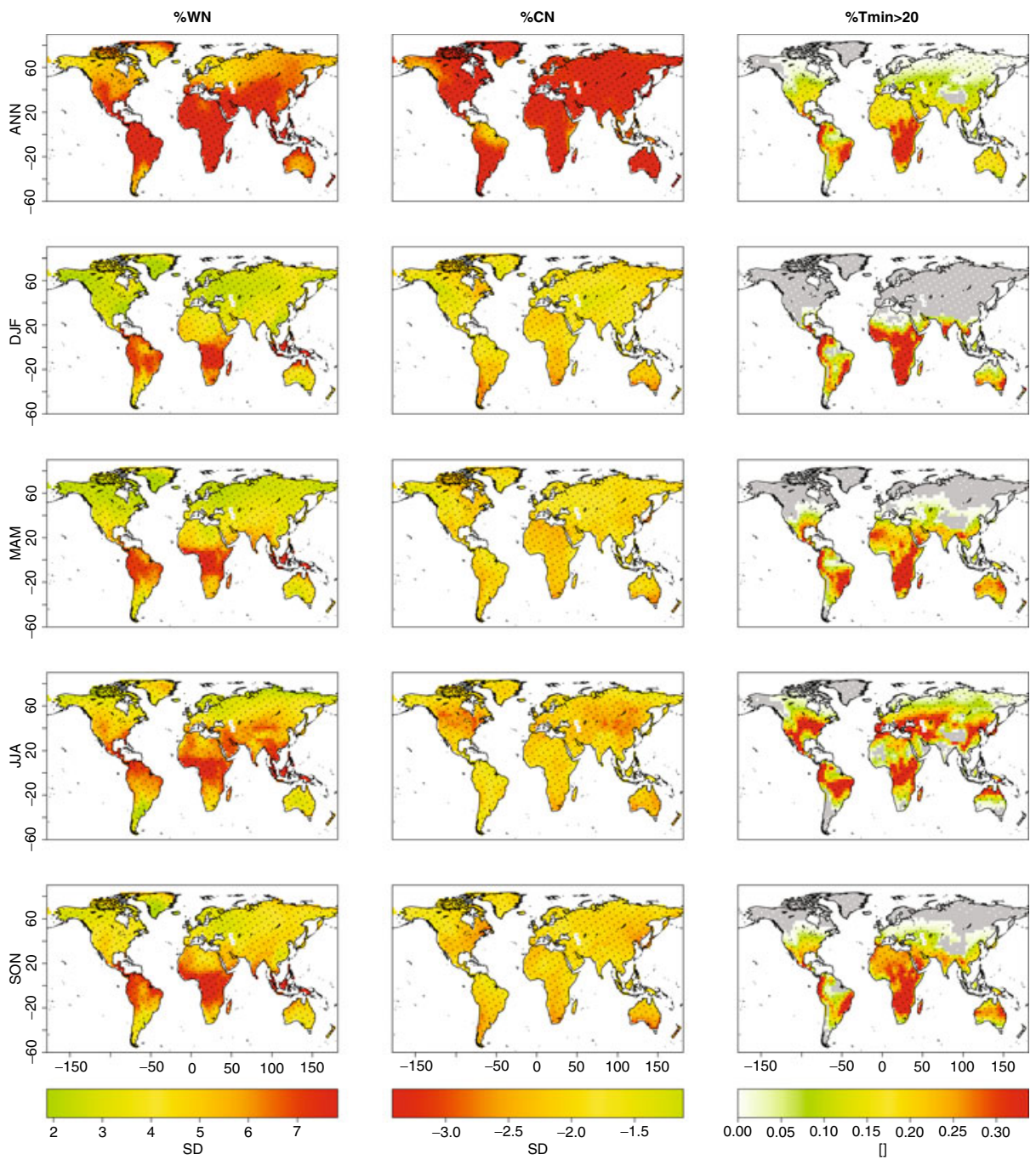

Fig. 4 Annual and seasonal changes of three indices for $T_{\min }$ : Fraction of warm nights, fraction of cold nights and tropical nights with $T_{\min }>20^{\circ} \mathrm{C}$. See Section 2.2 for details. White stippling indicates the areas where no GCM reaches the $20^{\circ} \mathrm{C}$ threshold in any of the two periods (1980-1999 and 20812100)

split in two. This shows the limited robustness of the estimators (which for the HWDImax index was already pointed to in Alexander et al. 2006). The annual HWDImax pattern is consistent with the pattern found in T06 for the smaller GCM ensemble.

On the annual scale, patterns of change in HWDImean agree to some extent with those for HWDImax, despite significant discrepancies on the seasonal time scale, for example over the Sahel in spring (MAM) or the Northern high latitudes in SON. It is not clear which of the two indices is more meaningful. 

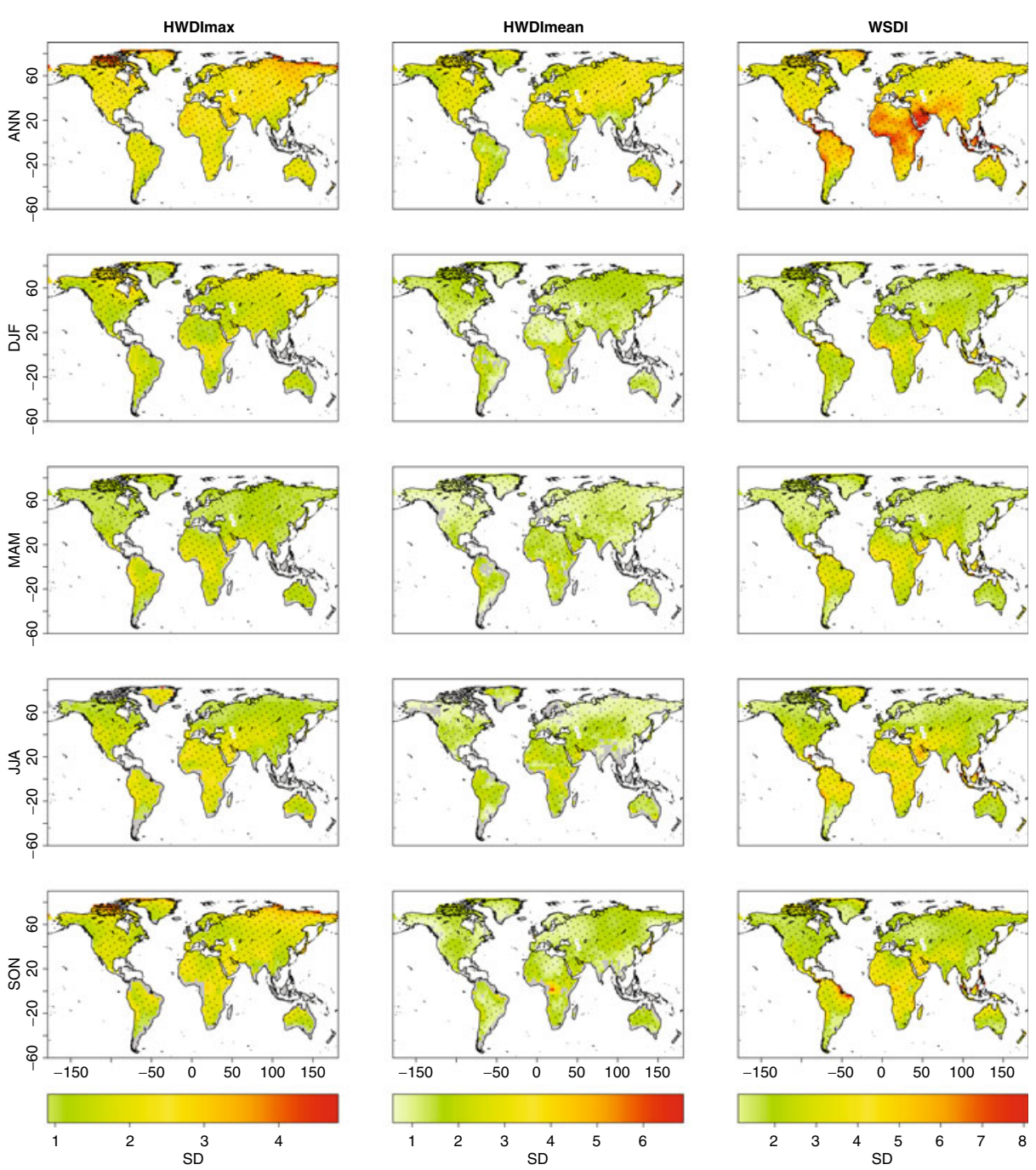

Fig. 5 Annual and seasonal changes of three heatwave duration indices: maximum heatwave duration (HWDImax), average heatwave duration (HWDImean) and the warm spell duration index $(W S D I)$. See Section 2.2 for details

For the WSDI index, the dominant increase over the tropics in all seasons is probably due to the relatively low daily variability of temperature in that region (not shown). There, a climate which is on average warmer than the reference period will immediately lead to long periods in which the climatological $90 \%$-quantile is exceeded, while for example in the mid-latitudes the daily variability is larger, leading to higher climatological $90 \%$-quantiles with respect to the average climatological temperature. This is most visible in the JJA season.

Hence, to summarize the results on the projected changes in heatwave length, the differing index-dependent patterns do not provide a clear indication of which 
index is most appropriate for such assessments. It should also be noted that none of these indices consider the intrinsic persistence of hot days (which would need to be computed with respect to a quantile-based threshold of the given time period, rather than the reference period; see Lorenz et al. 2010, for a discussion of this issue). Nonetheless, all indices indicate an increase in heatwave length in most regions, consistent with the mean temperature increase, and the definitional issues are mostly relevant for the assessment of possible "hot spots" of changes in heatwave length. There are, however, some regions that display only small or even insignificant increases in heatwave length for some of the indices, mostly on the seasonal time scale. This is in particular the case in Southern South America in JJA for all indices, in the Malay Archipelago and Madagascar for HWDImax and HWDImean in all seasons as well as on the annual time scale, in the Amazon region in MAM for HWDImean, in Southeast and Southern Asia in JJA and SON for HWDImean, and in Scandinavia and Alaska in JJA for HWDImean.

Overall, the close agreement between the patterns in T06 and our analysis of the complete IPCC AR4 ensemble confirms the robust representation of the temperature-related extremes in the GCMs. The geographical distribution of these changes also seems to be rather independent of the underlying emission scenario (the patterns in T06 are derived from SRES-A1B simulations, whereas our analysis uses A2 simulations). As mentioned in the Introduction, T06 similarly found for their smaller GCM ensemble that the patterns of change in the extreme indices are robust across different emission scenarios. For the assessment of changes in heatwave length, the choice of index appears to lead to more uncertainty in the projections than the number of considered GCMs, since our annual HWDImax patterns agree well with the corresponding analysis from T06.

\subsection{Precipitation}

Figure 6 shows the relative changes of three precipitation quantiles, which are derived from annual and seasonal averages (not from daily values like for temperature) for more robust estimates. The regional relative changes agree very closely between all quantiles for all seasons, which means that on this longer time scale for each season the distribution is stretched or shrunk by similar factors for all quantiles. The maps show increasing precipitation over Northern mid and high latitudes, equatorial East Africa and parts of equatorial South America. Decreases are found over Southern Europe and the Mediterranean, the Middle East, Southern Africa and parts of the Southern US. Spatially, this decrease is most consistently simulated in boreal spring. On the annual time scale, these findings essentially agree with the pattern of change of maximum five-day precipitation in T06. Large areas are left blank, reflecting the low agreement on the sign of the changes among the models. Stippling is also much less frequent compared to the temperature indices maps and is limited to the Northern high latitudes.

The general patterns of increase and decrease are also reflected in the three precipitation indices analyzed in Fig. 7 (wet day intensity, fraction of days above the $95 \%$-quantile of daily wet day precipitation and fraction of days with precipitation above $10 \mathrm{~mm}$ ). For the two normalized indices of this plot (wet day intensity and pr $>10 \mathrm{~mm}$ ) the seasonal signals are weaker than the annual one due to the higher seasonal standard deviations used for the normalization. Also for these two indices, 

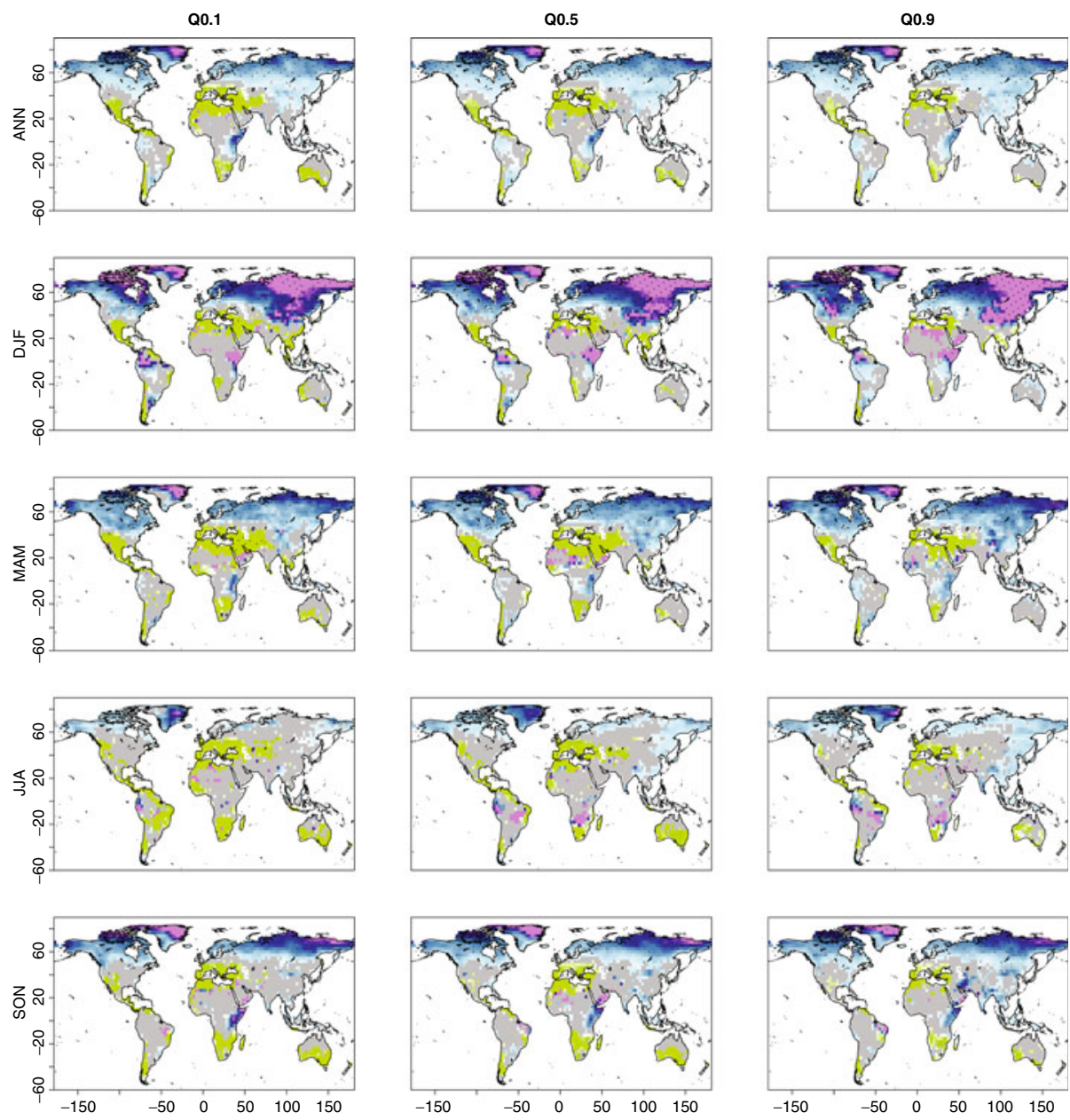

Fig. 6 Relative changes of three precipitation quantiles, derived from annual $(A N N)$ and seasonal $(D J F, M A M, J J A, S O N)$ precipitation averages

the corresponding patterns in T06 are similar to our annual maps. High agreement among the models as shown by the stippling is restricted to the areas with strongest signals, for example the Northern high latitudes on the annual time scale and partly also in winter (DJF) and spring (MAM). For the dry areas in Northern and Southern Africa, Australia, Middle East, Southern US and, depending on the season, also large parts of Eurasia the maps are left blank, again reflecting the low agreement of the models on the sign of change in these regions.

The commonly used $10 \mathrm{~mm}$ threshold for the definition of heavy precipitation (also used in T06) is questionable since it is not necessarily extreme everywhere and its evaluation in climate model simulations can be hampered by geographically 

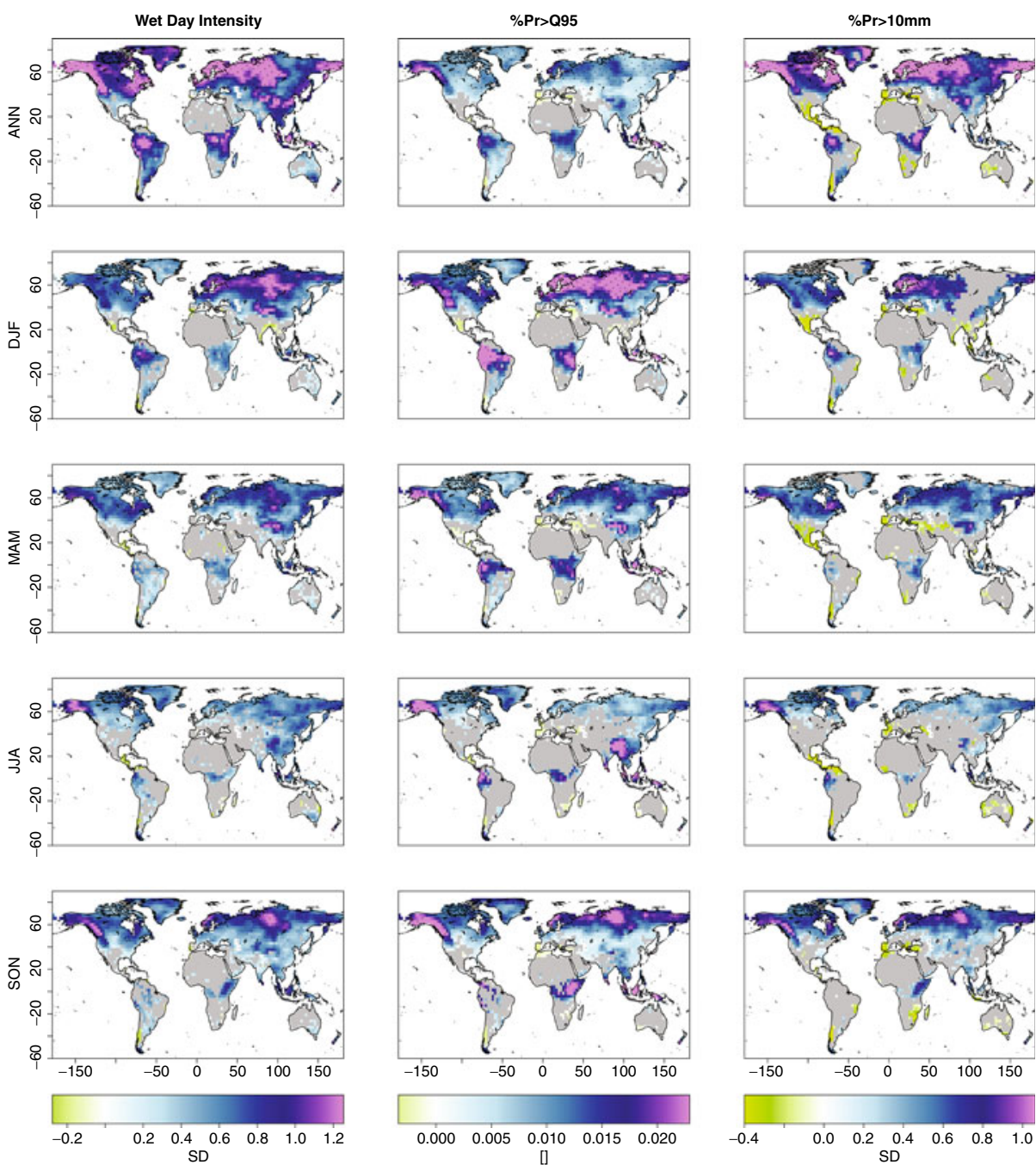

Fig. 7 Annual and seasonal changes of three precipitation indices: Wet day intensity, fraction of days with precipitation above the $95 \%$-quantile of daily wet day precipitation and fraction of days with $\mathrm{pr}>10 \mathrm{~mm}$. See Section 2.2 for details

uneven model biases. The pr $>q 95$ index for heavy precipitation alleviates these problems. Its patterns show increases in the same regions as the $\mathrm{pr}>10 \mathrm{~mm}$ index, although the patterns are not identical. Maximum increases exceed 2 percentagepoints, which is a large signal, since only $5 \%$ of the wet days during the reference period define this event. The decreases seen for the $\mathrm{pr}>10 \mathrm{~mm}$ index in some regions and seasons are less clear for the pr $>q 95$ index, compare e.g. Mexico, Southern Europe and the Middle East in boreal spring and autumn.

Note that we investigate here only changes in relatively moderate extremes. The study by Kharin et al. (2007) analyzed changes in 20-year return levels of annual 
24 h-precipitation extremes based on A1B simulations of the IPCC AR4 ensemble. That study also shows increases in most regions of the world, but their geographical patterns of changes in extremes differ in some aspects, in particular regarding a highest increase in Southern and Southeast Asia, which is not present for the indices analyzed in the present study.

\subsection{Dryness}

Figure 8 combines change of dryness measures from two variables: the precipitationbased index of consecutive dry days (CDD) and average soil moisture. The CDD index has been extensively used in the climate literature for the assessment of dryness (e.g., Frich et al. 2002; Alexander et al. 2006, T06). However, it is only based on precipitation and does not directly include the impact of enhanced evapotranspiration as driver for droughts. Although rain-free periods will tend to have enhanced evapotranspiration, the radiation and temperature anomalies during these periods will also strongly impact the resulting evapotranspiration (e.g., Easterling et al. 2007; Corti et al. 2009). Hence it is important to assess to which extent this index compares with modelled changes in soil moisture, which are more relevant for agricultural drought (e.g., Wang 2005; Dai 2010).

The CDD patterns correspond basically-despite some regional differencesto the overall trends of precipitation seen for the quantiles in Fig. 6: Decreasing dryness in the Northern high latitudes and increasing dryness in Southern US, Southern Europe, the Mediterranean, South Africa, Australia and some parts of South America. Here as well, for large areas the models show poor agreement. A unique regional feature of this index is the strong CDD length decrease in Eastern Siberia, which is found for boreal winter, fall and the annual analysis. The annual pattern matches the CDD pattern from T06, although the average changes in our larger GCM ensemble are a little weaker than in the T06 ensemble.

The analysis of soil moisture (mrso) changes, which is expressed in units of standard deviations to account for the different depths over which the GCMs integrate the soil moisture (Wang 2005), reveals some correspondences between the CDD and soil moisture tendencies. In particular, the two measures consistently indicate enhanced dryness on the annual time scale in the Mediterranean and parts of Central Europe, in Mexico, and in parts of South Africa (induced by anomalies in DJF and MAM in Mexico, JJA and SON in the Mediterranean and Central Europe, and in MAM, JJA and SON in South Africa). Both indices also point at increases in dryness in part of Brazil in SON. Consistent increases in soil moisture are limited to parts of Eurasia in boreal winter and spring. Furthermore, several regions with increases in CDD do not show consistent changes in soil moisture (e.g., Australia in JJA and SON), and overall the patterns are very patchy for soil moisture due to lack of agreement in the respective sign of change in the models. This shows the large uncertainty involved in the modeling of land surface processes in current climate models (as known from several analyses, e.g., Boe and Terray 2008; Seneviratne et al. 2010; Orlowsky and Seneviratne 2010). The analysis agrees with the findings in Wang (2005), although their results are based on a different selection of GCMs and compare a different pair of experiments and periods (after-stabilization following the SRES A1B scenario vs. pre-industrial simulations). The regions displaying consistent increases in dryness based both on the CDD and often soil moisture analysis are 

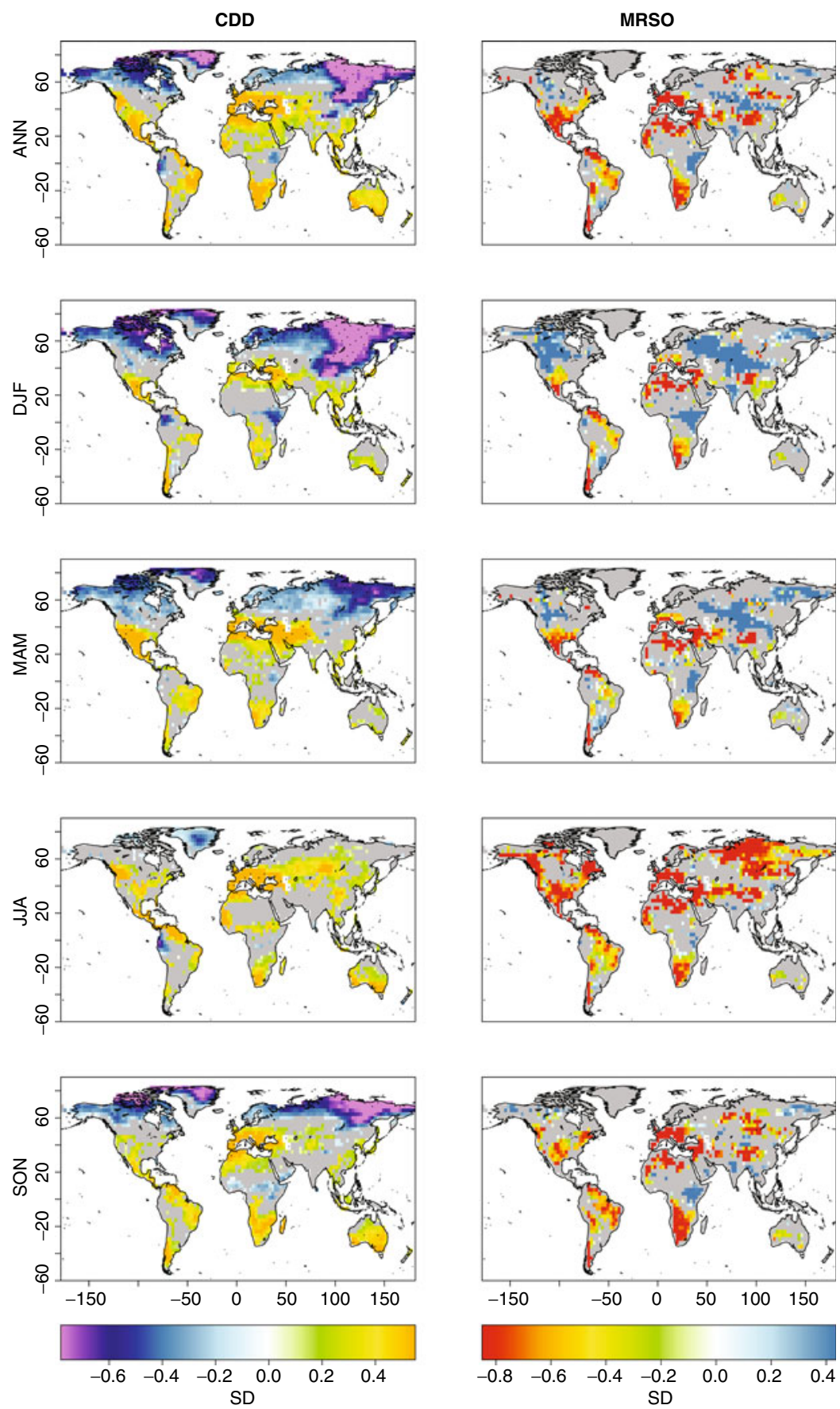

Fig. 8 Annual and seasonal changes of two dryness indicators: Consecutive dry days $(C D D$, days with $\mathrm{pr}<1 \mathrm{~mm}$ ) and average soil moisture (mrso). See Section 2.2 for details 
also identified as hot spots for changes in dryness based on other measures in, e.g., Sheffield and Wood (2008) and Dai (2010).

As a consequence of rising temperatures and radiation, evapotranspiration increases over large parts of the world, see Fig. 9. The regions presenting consistent increases in dryness based on both the CDD and soil moisture analysis often display decreased evapotranspiration, which is consistent with an enhanced soil moisture limitation in these areas. This decrease of evapotranspiration is strongest and most consistent in Southern Europe, the Southern US and the Middle East in MAM and JJA. Thus, evapotranspiration, although not being a dryness index per se, is a relevant variable both as a driver of drought and as diagnostic of drought (i.e.
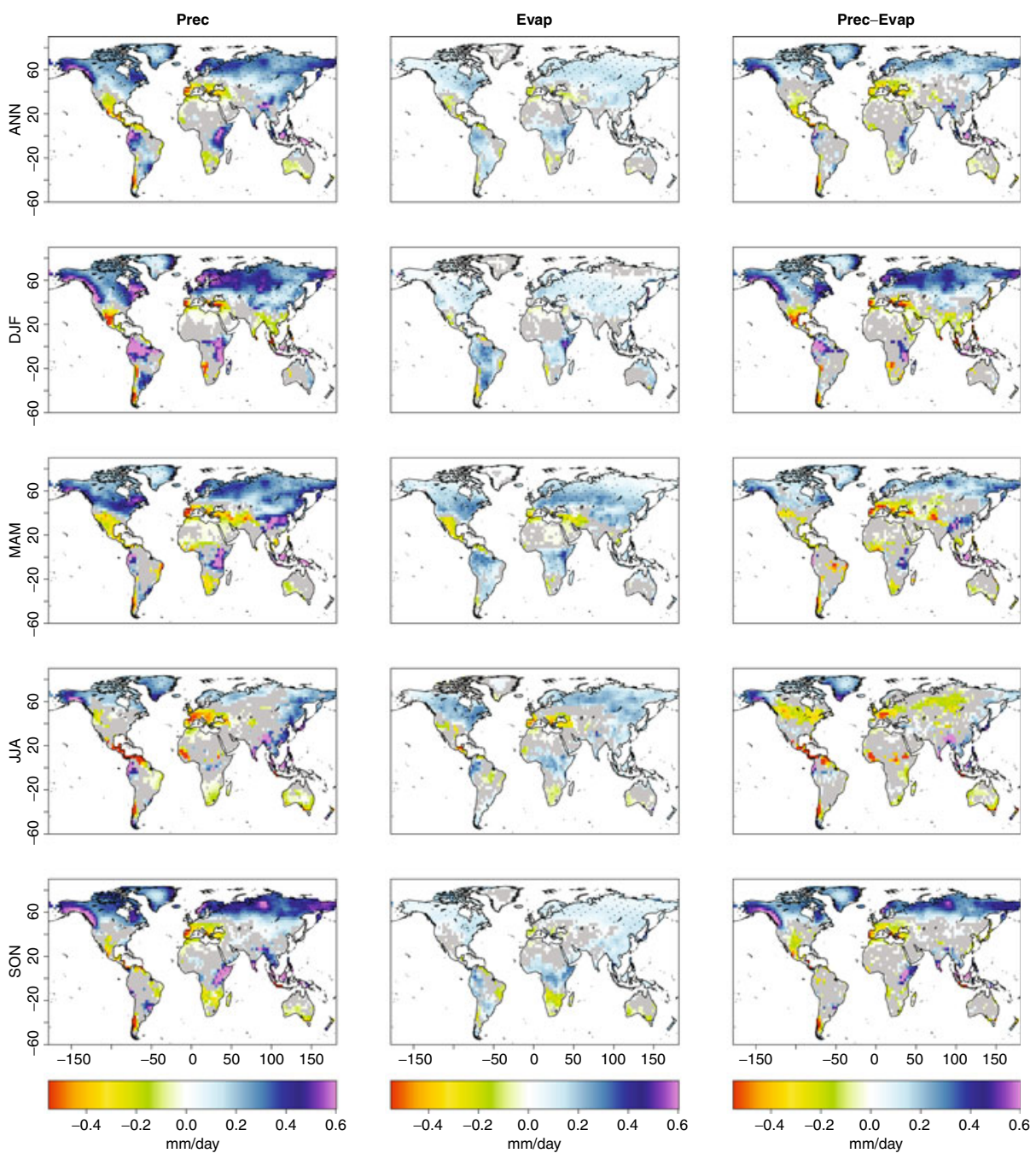

Fig. 9 Annual and seasonal changes of precipitation, evapotranspiration, and their difference (precipitation minus evapotranspiration). See Section 2.2 for details 
when soil moisture becomes limiting for evapotranspiration). The Mediterranean region, central Europe, southern North America, southern Africa, and southern Chile are the main regions where the atmospheric water input (precipitation minus evapotranspiration) decreases throughout the year. These are also some of the regions which show the most consistent soil moisture depletion in all seasons, while in general the patterns of soil moisture changes correspond only partially to the patterns of changing atmospheric water input (emphasizing the role of river runoff for the terrestrial water balance).

Note that the partial discrepancies of changes in dryness assessed either by analysis of CDD or soil moisture highlight that the choice of dryness index can be critical for the assessment of drought projections (see also Burke and Brown 2008). In the case of the projected annual changes in CDD, the close agreement between the patterns in T06 and our analyses demonstrate their robustness for different emission scenarios, at least for the regions where the models reasonably agree on the sign of the changes.

\section{Scaling of regional and seasonal extremes with global warming}

An important question in the investigation of changes in extreme events is whether they can be described by a scaling of the average change in mean climate, for example, whether the changes of the $90 \%$-quantiles of temperature are (possibly linearly) related to changes of mean temperature, either with respect to global or regional averages. We address this question for $T_{\max }$ with a decomposition of the annual and seasonal regional changes of the $10 \%$ - and $90 \%$-quantiles,

$$
\Delta_{\text {SEAS }} Q x x=\underbrace{\underbrace{\Delta_{\text {SEAS }} Q x x}_{f_{\text {extr }}} \underbrace{\frac{\Delta_{\text {SEAS }} Q 50}{\Delta_{\text {ANN }} Q 50}}_{f_{\text {seas }}} \underbrace{\frac{\Delta_{\text {ANN }} Q 50}{\bar{\Delta}_{\text {ANN }} Q 50}}_{f_{\text {reg }}} \overline{\Delta_{\text {ANN }} Q 50,}}_{f_{\text {tot }}}
$$

where SEAS is a placeholder for ANN, DJF, MAM, JJA or SON, $Q x x$ is either $q 10$ or $q 90$, and $\overline{\Delta_{\mathrm{ANN}} Q 50}$ denotes the global average of the annual $q 50$ change (as a substitute for global warming). The factor $f_{\text {tot }}$ in Eq. 1 refers to the overall scaling between the seasonal change in a given $T_{\max }$ quantile at the regional scale and the global warming substitute, and is subdivided in three contributing factors: $f_{\text {reg }}$, which represents the scaling of the regional warming with the global warming; $f_{\text {seas }}$, which gives the seasonal scaling of this regional warming; and $f_{\text {extr }}$, which describes the scaling of the extreme temperature quantiles with the regional seasonal median warming. Note that these ratios are calculated for each model individually before averaging over the ensemble.

To assess the agreement of these scaling factors across the GCMs, we calculate the inter-GCM standard deviation $\sigma$ at each grid point. The maps of these standard deviations are provided in the Electronic Supplementary Material (Figs. S1-S3). In Figs. 10, 11 and 12, we mark the regions where $\left|f_{\mathrm{xxx}}-1\right|>\sigma$ by stippling.

The total factors $f_{\text {tot }}$ are shown in Fig. 10. The patterns naturally correspond to the quantile analysis of Fig. 1, they however indicate where the quantile changes are weaker or stronger than the average global warming. For example, the low temperature quantile increases more than global warming (by a factor of more than 2) in 

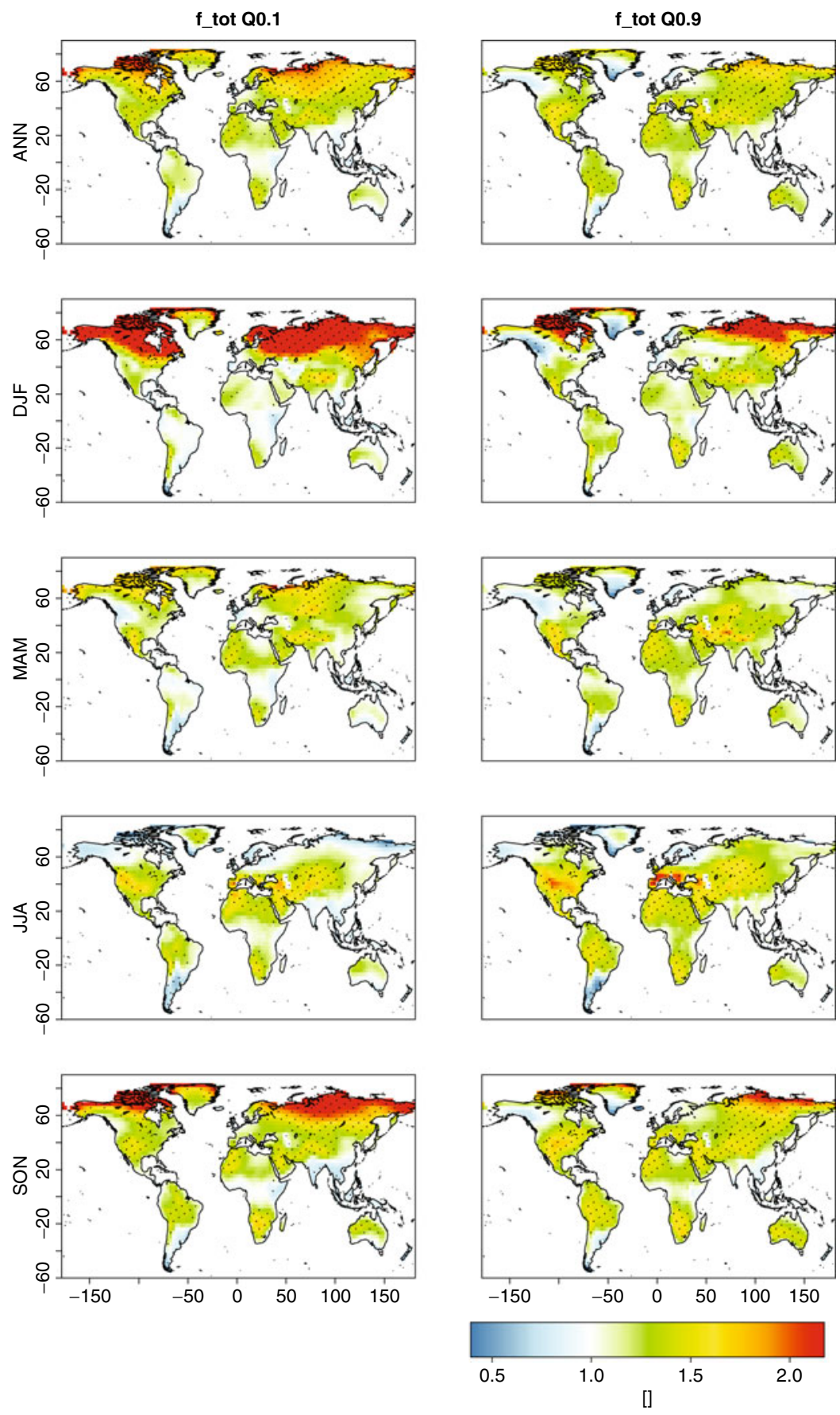

Fig. 10 Quantile changes of daily $T_{\max }$ over entire years and individual seasons, scaled by the globally and annually averaged increase of the median $T_{\max }$. Stippling is used to indicate regions where $\left|f_{\text {tot }}-1\right|>\sigma$, compare to Fig. S1 in the Electronic Supplementary Material 

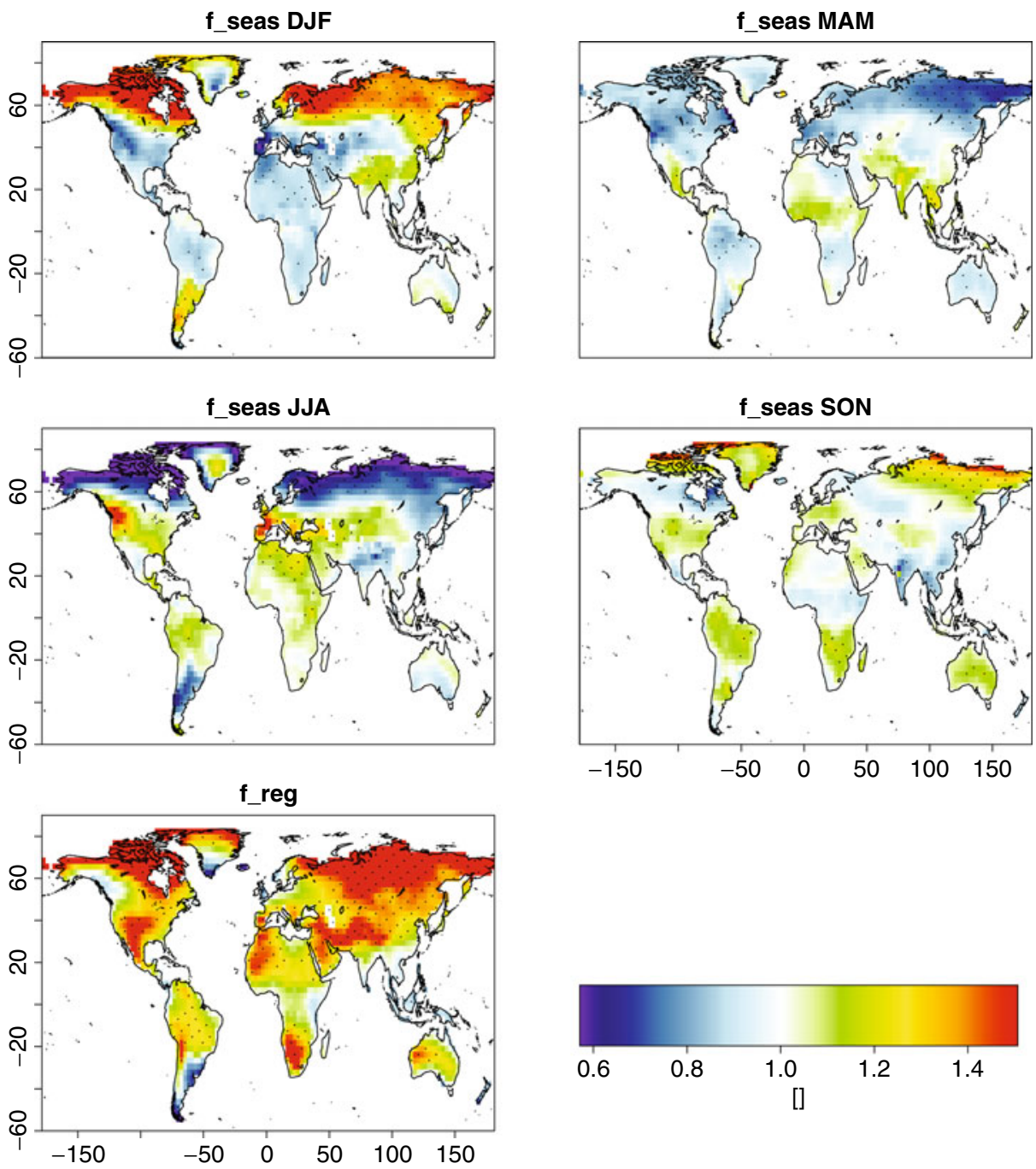

Fig. 11 Upper two rows: Seasonal amplification patterns, that is the seasonal changes of median $T_{\max }$ scaled by the annual change of median $T_{\max }$. Bottom left: pattern of regional change in $T_{\max }$, expressed as the regional annual change of the $T_{\max }$ median scaled by the globally averaged increase of the median $T_{\max }$. Stippling is used to indicate regions where $\left|f_{\mathrm{xxx}}-1\right|>\sigma$, compare to Fig. S2 in the Electronic Supplementary Material

the Northern high latitudes. Seasonally this is most pronounced for boreal winter and fall, hinting at the role of decreasing snow and a related positive temperaturealbedo feedback in this area (see also Section 3.1). For the high temperature quantile, the annual increase displays the highest scaling factor in Southern Europe, the Mediterranean and central US (factor of about 2), which is mostly induced by warming in boreal summer and fall. This increase of the extreme temperatures is thus related to depleted soil moisture and enhanced dryness (compare to Fig. 8), as also discussed in Section 3.1. 

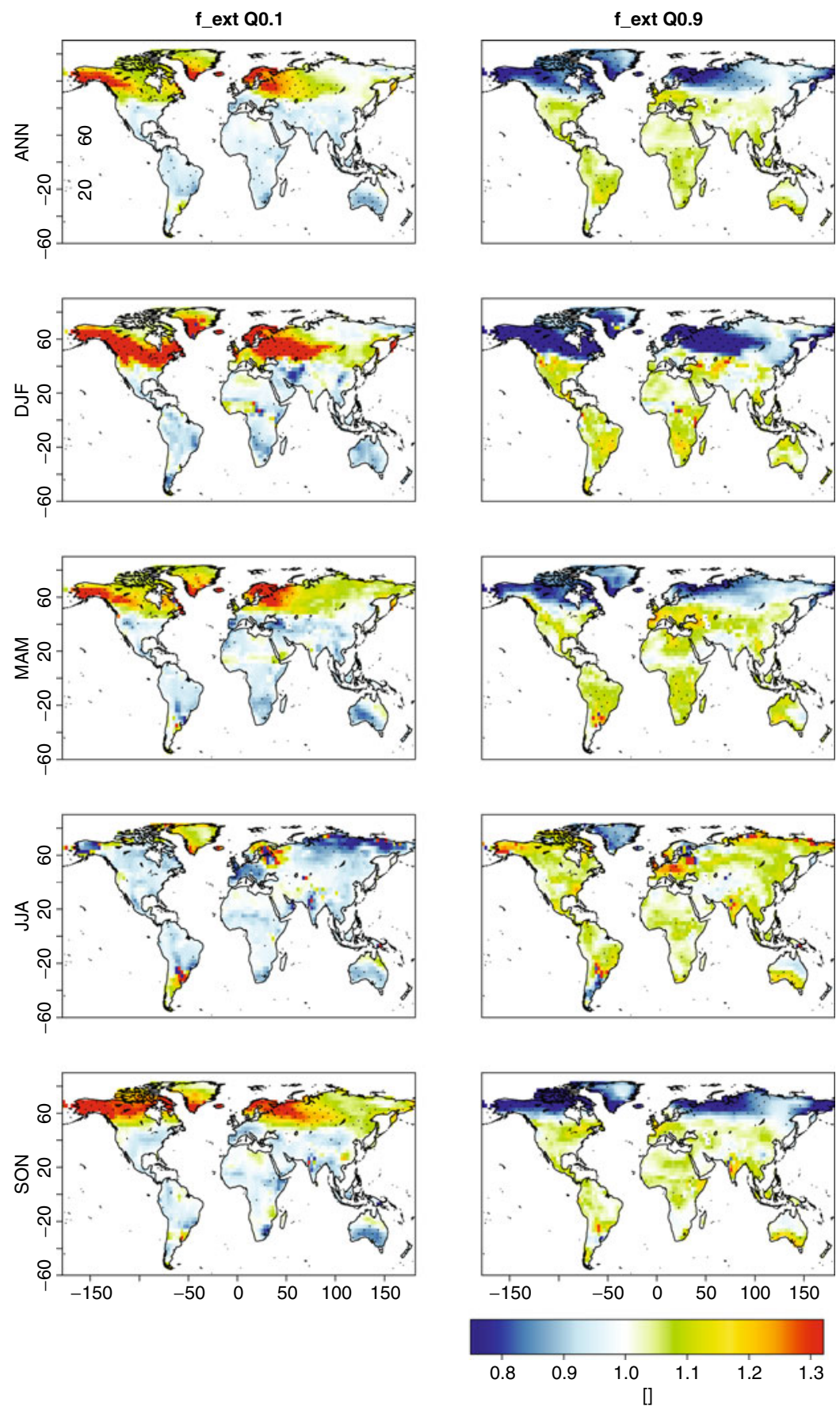

Fig. 12 Seasonal changes in the Q10 and Q90 quantiles of $T_{\max }$ scaled by the seasonal changes of median $T_{\max }$. Stippling is used to indicate regions where $\left|f_{\text {extr }}-1\right|>\sigma$, compare to Fig. S3 in the Electronic Supplementary Material 
Generally, a scaling factor above 1.5 exceeds the inter-GCM standard deviation $\sigma$. Large seasonal variations are found in the $\sigma$ patterns (Fig. S1 in the Electronic Supplementary Material), for example large $\sigma$ values in the high Northern latitudes in DJF for the low temperature quantile and over the US in JJA. The regions of high $\sigma$ do not necessarily coincide with the regions of large average scaling factors in Fig. 10. Note that some of the regions where influences of snow or soil moisture are relevant for changes in temperature extremes (that is, large parts of Eastern Eurasia in DJF and the Mediterranean and parts of the US in JJA, compare Section 3.1) display a high inter-GCM variability of $f_{\text {tot }}$. This highlights once more the known uncertainties in current GCMs with respect to land surface processes.

While the $f_{\text {reg }}$ plot in Fig. 11 (bottom left) reproduces the annual change of the $50 \%$-quantile in Fig. 1 , the seasonal $f_{\text {seas }}$ plots show that much of the total changes of the two chosen extreme quantiles is due to seasonal dynamics. In fact, the prominent features of the seasonal $10 \%$ - and $90 \%$-quantile plots in Fig. 10 show very strong correspondences with those of the $f_{\text {seas }}$ plots of Fig. 11. For example, the relatively low JJA increase seen in the $10 \%$-quantile over the arctic region and the relatively strong increase over the Mediterranean for the $90 \%$-quantile are both present in the $f_{\text {seas }}$ for JJA.

Regarding the inter-GCM variability of these scaling factors, $f_{\text {reg }}$ shows a signal which is larger than the corresponding $\sigma$ over most of the global land surface. Exceptions are continental Africa, parts of Central, Eastern and Northern Europe, parts of South East Asia and the North-West of the US. For the seasonal scaling factors, the most robust feature in this comparison is over Siberia in all seasons. In other regions these scaling factors exceed $\sigma$ only in single seasons. Like for $f_{\text {tot }}$, the patterns of large inter-GCM $\sigma$ do not necessarily correspond to the regions of large scaling factors (Fig. S2 in the Electronic Supplementary Material).

Regarding the amplification of the extreme temperature ranges captured by $f_{\text {extr }}$ (Fig. 12) the picture is less clear. The Northern high latitudes see a much higher increase of low temperatures compared to regional warming. This increase takes place mainly in boreal spring and fall, while for the rest of the globe the low $T_{\max }$ quantile increases less than the regional seasonal warming. For the high $T_{\max }$ quantile, essentially one hot spot appears where the quantile warms faster than the regional warming: Central and Southern Europe. The European increase takes place mainly in boreal summer and fall, which thus further increases the effect of the seasonal scaling in this region.

Consistent scaling factors with respect to inter-GCM $\sigma$ are restricted to Western Russia and the Northern US with Canada, and this consistency almost vanishes for boreal spring and summer. Compared to the other scaling factors, the agreement between the GCMs is the lowest for $f_{\text {extr }}$. Also for this scaling factor, the regions of large $\sigma$ do not map directly onto the regions of large $f_{\text {extr }}$ values (compare to Fig. S3 in the Electronic Supplementary Material).

\section{Conclusions}

The aim of this study is to provide a systematic analysis of changes in extreme events in the entire IPCC AR4 (CMIP3) GCM ensemble, with a focus on seasonal and regional changes. Although the coarse spatial and temporal resolution of this 
simulation ensemble means important limitations for the analysis of changes in extreme events, it constitutes for many regions of the world the only multi-model data basis regarding projections in these extremes. Keeping the limitations in mind, our focus is on general tendencies of changes in extreme events in the models, restricting the discussion to tendencies on which at least $66 \%$ of the models agree. Previous studies which performed similar or overlapping analyses, in particular T06, were limited to a subset of the GCM ensemble considered in this analysis. Moreover, we significantly expanded the analysis of heatwave and dryness indices compared to T06, beside the seasonal and regional focus of our investigation. Our study thus complements the T06 study in that it grounds the analysis on a more complete data basis.

We analyse patterns of change from present-day to future climate conditions by comparing 2081-2100 to 1980-1999 patterns. The future patterns are derived from simulations driven by the A2 emission scenario. Our analysis includes extreme indices for maximum and minimum air temperature $\left(T_{\max }\right.$ and $\left.T_{\min }\right)$, precipitation and average changes of soil moisture and evapotranspiration in relation to dryness. The analyses for indices also considered in T06 are essentially consistent between the two studies, despite the differences in considered model ensembles and emission scenarios (A1B in T06).

Several hot spots of changes in extremes can be identified from the analysis: the Mediterranean area experiences an increase in heat extremes such as high $T_{\max }$ quantiles, number of warm days and heatwaves together with increasing dryness found in precipitation, soil moisture and evapotranspiration. This points at the role of depleting soil moisture as the link between drying and heating in this region (e.g., Seneviratne et al. 2006; Diffenbaugh et al. 2007). The fact that the Mediterranean region appears as a hot spot of future climate change has also been recently highlighted in Giorgi and Lionello (2008). Furthermore, Fischer and Schär (2010) point to a high consistency of regional climate model projections with respect to changes in heatwave patterns in this region. The Northern high latitudes see an increase of precipitation intensity and heavy precipitation together with decreasing dryness indices. Low temperature quantiles rise much more strongly than average global warming in this region, probably due to a positive albedo-temperature feedback triggered by snow retreat. Correspondingly, $T_{\text {min }}$ generally rises in the Arctic region, especially during winter (DJF).

The models agree almost everywhere and for all seasons on the sign of changes of temperature indices and quantiles, but changes in precipitation are more uncertain. Changes that may be termed as very likely according to the IPCC uncertainty language (agreement of at least $90 \%$ of the models on the sign, conditional on sufficient trust in the model performances, see Section 2.2) are usually only found in the Northern high latitudes. For large regions in the tropics, and even in the mid-latitudes, less than $66 \%$ of the models agree on the sign of changes. This is particularly true for the seasonal analysis. For soil moisture an agreement between the models does hardly exist over most parts of the globe (some exceptions with increased dryness are found in the Mediterranean region, Central Europe, southern North America, northern South America, southern Chile, and southern Africa).

While most extreme indices are easy to interpret, the quantification of heatwaves appears ill-defined. At least the standard indices analyzed here do not show consistent patterns, which can be understood from the different threshold definitions they 
are based on. Generally, heatwave assessment for the tropics is difficult, since dayto-day temperature variability is low. We also find that analyses regarding changes in dryness depend on the choice of the employed index. Although common areas are projected to become drier both based on the CDD and soil moisture analyses, our results suggest that CDD-only analyses may be underestimating the level of uncertainty associated with changes in drought characteristics, when considering e.g. changes in agricultural drought rather than meteorological drought.

A new feature of our analysis compared to previous global studies of changes in extremes (e.g. T06) is the fact that also seasonal changes in extremes are considered. The results reveal significant seasonal variations in the projected changes, and overall a higher uncertainty on the seasonal vs. the annual time scale.

In the context of the frequently discussed global $2{ }^{\circ} \mathrm{C}$ warming target (e.g. Meinshausen et al. 2009), a natural question is whether (seasonal) extreme events scale in any obvious manner with global or regional annual-mean warming. We address this question by decomposing the changes of low and high $T_{\max }$ quantiles into factors of regional, seasonal and extreme amplification of global warming. Our analysis reveals that a significant contribution to the total quantile changes comes from the seasonal amplification of regional warming, once more underlining the importance of a seasonal perspective on extreme events.

Soon the next generation of simulations for the 5th assessment report of the IPCC will become available. The present analysis will also support the evaluation of these future simulations, and differences between the outcomes will be helpful for evaluating impacts of model and forcing changes between these two GCM ensembles (such as the representation of biogeochemical feedbacks and the inclusion of land use changes). The results of this study can hopefully serve as a baseline to which future simulations can be compared, and as an overview of general tendencies in extremes relevant for adaptation and mitigation planning.

Acknowledgements We acknowledge the international modeling groups for providing their data for analysis, the Program for Climate Model Diagnosis and Intercomparison (PCMDI) for collecting and archiving the model data, the JSC/CLIVAR Working Group on Coupled Modelling (WGCM) and their Coupled Model Intercomparison Project (CMIP) and Climate Simulation Panel for organizing the model data analysis activity, and the IPCC WG1 TSU for technical support. Support from the German Science Foundation DFG (grant Or256/1-1)a and ETH Zurich is acknowledged. The authors thank Neville Nicholls, Dave Easterling, Clare Goodess, Markus Reichstein, Carolina Vera and Xuebin Zhang for useful discussions.

Open Access This article is distributed under the terms of the Creative Commons Attribution Noncommercial License which permits any noncommercial use, distribution, and reproduction in any medium, provided the original author(s) and source are credited.

\section{References}

Alexander L, Zhang X, Peterson T, Caesar J, Gleason B, Tank A, Haylock M, Collins D, Trewin B, Rahimzadeh F, Tagipour A, Kumar K, Revadekar J, Griffiths G, Vincent L, Stephenson D, Burn J, Aguilar E, Brunet M, Taylor M, New M, Zhai P, Rusticucci M, Vazquez-Aguirre J (2006) Global observed changes in daily climate extremes of temperature and precipitation. J Geophys Res 111:D05109

Beniston M, Stephenson DB, Christensen OB, Ferro CAT, Frei C, Goyette S, Halsnaes K, Hollt T, Jylhä K, Koffi B, Palutikof J, Schöll R, Semmler T, Woth K (2007) Future extreme events 
in European climate: an exploration of regional climate model projections. Clim Change 81: $71-95$

Boe J, Terray L (2008) Uncertainties in summer evapotranspiration changes over Europe and implications for regional climate change. Geophys Res Lett 35:L05702

Burke EJ, Brown SJ (2008) Evaluating uncertainties in the projection of future drought. J Hydrometeorol 9(2):292-299. doi:10.1175/2007JHM929.1

Corti T, Muccione V, Köllner-Heck P, Bresch D, Seneviratne S (2009) Simulating past droughts and associated building damages in France. Hydrol Earth Syst Sci 13(9):1739-1747

Dai A (2010) Drought under global warming: a review. WIREs Clim Change. doi:10.1002/wcc.81

Diffenbaugh NS, Pal JS, Giorgi F, Gao X (2007) Heat stress intensification in the Mediterranean climate change hotspot. Geophys Res Lett 34:L11706. doi:10.1029/2007GL030000

Easterling DR, Wallis TWR, Lawrimore JH, Heim J, Richard R (2007) Effects of temperature and precipitation trends on U.S. drought. Geophys Res Lett 34(20):L20709. doi:10.1029/2007GL031541

Fischer EM, Schär C (2010) Consistent geographical patterns of changes in high-impact European heatwaves. Nature Geosci 3(6):398-403. doi:10.1038/ngeo866

Frich P, Alexander L, Della-Marta P, Gleason B, Haylock M, Tank AK, Peterson T (2002) Observed coherent changes in climatic extremes during the second half of the twentieth century. Clim Res 19:193-212

Giorgi F, Lionello P (2008) Climate change projections for the Mediterranean region. Glob Planet Change 63(2-3):90-104. doi:10.1016/j.gloplacha.2007.09.005, URL http://www.sciencedirect. com/science/article/B6VF0-4PTMXVP-3/2/16911ccab3b18a182d66f8266a15b6cc

Halsnaes K, Kühl J, Olesen JE (2007) Turning climate change information into economic and health impacts. Clim Change 81:145-162

Hirschi M, Seneviratne SI, Alexandrov V, Boberg F, Boroneant C, Christensen OB, Formayer H, Orlowsky B, Stepanek P (2011) Observational evidence for soil-moisture impact on hot extremes in southeastern Europe. Nature Geosci 4(1):17-21. doi:10.1038/ngeo1032

IPCC (2007) Climate change 2007: the physical science basis. In: Solomon S, Qin D, Manning M, Marquis M, Averyt K, Tignor MMB, LeRoy Miller Jr, H, Chen Z (eds) Contribution of working group I to the fourth assessment report of the IPCC. Cambridge University Press, Cambridge

Jaeger E, Seneviratne S (2010) Impact of soil moisture-atmosphere coupling on European climate extremes and trends in a regional climate model. Clim Dyn. doi:10.1007/s00382-010-0780-8

Kharin VV, Zwiers FW, Zhang X, Hegerl GC (2007) Changes in temperature and precipitation extremes in the IPCC ensemble of global coupled model simulations. J Clim 20(8):1419-1444. doi:10.1175/JCLI4066.1

Knutti R, Furrer R, Tebaldi C, Cermak J, Meehl GA (2010) Challenges in combining projections from multiple climate models. J Clim 23(10):2739-2758. doi:10.1175/2009JCLI3361.1

Le Quere C, Raupach MR, Canadell JG, Marland G et al (2009) Trends in the sources and sinks of carbon dioxide. Nature Geosci 2(12):831-836. doi:10.1038/ngeo689

Lenton T, Held H, Kriegler E, Hall J, Lucht W, Rahmstorf S, Schellnhuber H (2008) Tipping elements in the Earth's climate system. Proc Natl Acad Sci 105(6):1786-1793

Loarie S, Duffy P, Hamilton H, Asner G, Field C, Ackerly D (2009) The velocity of climate change. Nature 462(7276):1052-1055

Lorenz R, Jaeger EB, Seneviratne SI (2010) Persistence of heat waves and its link to soil moisture memory. Geophys Res Lett 37(9):L09703. doi:10.1029/2010GL042764

Manning MR, Edmonds J, Emori S, Grubler A, Hibbard K, Joos F, Kainuma M, Keeling RF, Kram T, Manning AC, Meinshausen M, Moss R, Nakicenovic N, Riahi K, Rose SK, Smith S, Swart R, van Vuuren DP (2010) Misrepresentation of the IPCC CO2 emission scenarios. Nature Geosci 3(6):376-377. doi:10.1038/ngeo880

Mastrandrea M, Field C, Stocker T, Edenhofer O, Ebi K, Frame D, Held H, Kriegler E, Mach K, Matschoss P et al (2010) Guidance note for lead authors of the IPCC fifth assessment report on consistent treatment of uncertainties. Intergovernmental Panel on Climate Change (IPCC), URL https://www.ipcc-wg1.unibe.ch/guidancepaper/ar5_uncertainty-guidance-note.pdf

Meinshausen M, Meinshausen N, Hare W, Raper SCB, Frieler K, Knutti R, Frame DJ, Allen MR (2009) Greenhouse-gas emission targets for limiting global warming to $2^{\circ} \mathrm{C}$. Nature 458(7242):1158-1162. doi:10.1038/nature08017

Menzel A, Sparks T, Estrella N, Koch E, Aasa A, Ahas R, Alm-Kübler K, Bissolli P, Braslavská O, Briede A et al (2006) European phenological response to climate change matches the warming pattern. Glob Chang Biol 12(10):1969-1976 
Mueller B, Seneviratne S, Jimenez C, Corti T, Hirschi M, Balsamo G, Ciais P, Dirmeyer P, Fisher J, Guo Z et al (2011) Evaluation of global observations-based evapotranspiration datasets and IPCC AR4 simulations. Geophys Res Lett 38(6):L06402

Nakicenovic N, Swart R (2001) IPCC special report on emissions scenarios. Cambridge University Press, Cambridge

Orlowsky B, Seneviratne SI (2010) Statistical analyses of land-atmosphere feedbacks and their possible pitfalls. J Clim 23(14):3918-3932

Patz JA, Campbell-Lendrum D, Holloway T, Foley JA (2005) Impact of regional climate change on human health. Nature 438(7066):310-317. doi:10.1038/nature04188

Seneviratne SI, Luethi AD, Litschi M, Schär C (2006) Land-atmosphere coupling and climate change in Europe. Nature 443:205-209

Seneviratne SI, Corti T, Davin EL, Jaeger EB, Hirschi M, Lehner I, Orlowsky B, Teuling AJ (2010) Investigating soil moisture-climate interactions in a changing climate: a review. Earth-Sci Rev 99(3-4):125-161

Sheffield J, Wood E (2008) Projected changes in drought occurrence under future global warming from multi-model, multi-scenario, IPCC AR4 simulations. Clim Dyn 31:79-105. doi:10.1007/s00382-007-0340-z

Sherwood SC, Huber M (2010) An adaptability limit to climate change due to heat stress. Proc Natl Acad Sci 107(21):9552-9555. doi:10.1073/pnas.0913352107, URL http://www.pnas.org/content/ 107/21/9552.abstract, http://www.pnas.org/content/107/21/9552.full.pdf+html

Tebaldi C, Hayhoe K, Arblaster JM, Meehl GA (2006) Going to the extremes—an intercomparison of model-simulated historical and future changes in extreme events. Clim Change 79(3):185-211

van Oldenborgh GJ, Drijfhout S, van Ulden A, Haarsma R, Sterl A, Severijns C, Hazeleger W, Dijkstra H (2009) Western Europe is warming much faster than expected. Clim Past 5:1-5

Wang G (2005) Agricultural drought in a future climate: results from 15 global climate models participating in the IPCC 4th assessment. Clim Dyn 25:739-753. doi:10.1007/s00382-005-0057-9

Zhang J, Wang WC, Wu L (2009) Land-atmosphere coupling and diurnal temperature range over the contiguous United States. Geophys Res Lett 36(6):L06706. doi:10.1029/2009GL037505

Zhang X, Hegerl G, Zwiers F, Kenyon J (2005) Avoiding inhomogeneity in percentile-based indices of temperature extremes. J Clim 18(11):1641-1651 